Sādhanā Vol. 39, Part 6, December 2014, pp. 1447-1469. (C) Indian Academy of Sciences

\title{
Effect of fine to coarse aggregate ratio on the rheology and fracture energy of steel fibre reinforced self-compacting concretes
}

\author{
MERT YÜCEL YARDIMCI ${ }^{1, *}$, BÜLENT BARADAN ${ }^{2}$ and \\ MEHMET ALI TAŞDEMIR ${ }^{3}$
}

${ }^{1}$ Civil Engineering Department, Gediz University, Seyrek 35665 Izmir, Turkey

${ }^{2}$ Civil Engineering Department, Dokuz Eylül University, Buca 35160 Izmir, Turkey

${ }^{3}$ Civil Engineering Department, Istanbul Technical University, Maslak 34469

Istanbul, Turkey

e-mail: myyardimci@gmail.com; mert.yardimci@gediz.edu.tr

MS received 17 October 2013; revised 15 February 2014; accepted 10 March 2014

\begin{abstract}
In this study, the influence of aggregate grading and steel fibre properties on the flow properties and fracture energy of steel fibre reinforced self-compacting concrete (SFRSCC) has been investigated. Two types of hooked-end steel fibres at three different dosages $\left(20,40\right.$ and $\left.60 \mathrm{~kg} / \mathrm{m}^{3}\right)$ were incorporated into self-compacting mixtures having similar paste contents but different fine to coarse aggregate (FA/CA) ratios $(0.94,1.72$ and 2.50 by weight $)$. Besides the flowability and passing ability of fresh concrete, the mechanical properties of hardened concrete including the fracture energy have also been investigated. The relations between flexural parameters and fibre orientation were established by image analysis technique. Test results showed that hooked-end steel fibre inclusion into the plain self-compacting concrete negatively affects the flowability and passing ability of the mixture. Increasing FA/CA ratio enhances these rheological parameters and provides better fibre orientation. On the other hand, increasing FA/CA ratio decreases the fracture energy of plain SCC mixtures and the fibre incorporated series which were less affected from fibre inclusion follow the same trend with the plain SCC. The proper FA/CA ratio for the best rheological and mechanical performance depends on the fibre content, aspect ratio and their influence on the flowability of the mixture. In order to obtain better fibre orientation and hence higher fracture energy, relatively higher FA/CA ratios should be used when the fibre content and aspect ratio are relatively high.
\end{abstract}

Keywords. Steel fibre; steel fibre reinforced self-compacting concrete; fracture energy; fibre orientation.

*For correspondence 


\section{Introduction}

Self-compactibility of cementitious materials became an important and desired material property in the last decade. Conventional fibre reinforced concrete requires a high degree of vibration effort to get full compaction and therefore the development of steel fibre reinforced self-compacting concrete offers several economic and technical benefits. Self-compactibility of fibred cementitious materials may also enhance the performance of the fibred composites by achieving more uniform fibre dispersion (Ozyurt 2005). On the other hand, many researchers stated that flow behaviour of SFRSCC mixtures differs from that of a plain SCC (Khayat 1999; Khayat \& Roussel 2000; Groth 2000; Grünewald \& Walraven 2001). Incorporation of fibres decreases the workability of SCC mixtures (Khayat 1999; Boulekbache et al 2009; El-Dieb \& Reda Taha 2012) and increases flow time (Groth 2000; Grünewald \& Walraven 2001). Furthermore, when the fibre content is increased, the relative plastic viscosity increases and filling ability decreases (Khayat \& Roussel 2000). Passing ability is another important rheological parameter which is negatively affected by the fibre addition (Khayat 1999). Not only the fibre content but also the fibre geometry (length and diameter of the fibres) affects the flow characteristics of steel fibre incorporated self-compacting mixtures. It was previously shown that, slump flow decreases and flow time increases with an increase in the fibre factor (Khayat \& Roussel 2000). It was concluded by Grünewald \& Walraven (2001) that a larger bar spacing compared with plain SCC is required to avoid the risk of blocking in fibre-reinforced mixtures. Grünewald \& Walraven (2001) also stated that the mixture composition of the reference mixture influences the maximum possible fibre content. Furthermore, dispersion and orientation of the fibres, which may affect the toughness characteristics of the fibre reinforced composites, are dependent on the yield stress of the fluid material (Boulekbache et al 2009) and greatly influenced by the rheological properties of SFRSCC (Löfgren 2005; Ferrara \& Meda 2006; Ferrara et al 2012). It was shown that the mix compositions mainly paste and mortar volume and the fibre type greatly influence the maximum possible fibre content (El-Dieb \& Reda Taha 2012).

On the other hand, high fibre content and high fibre aspect ratios are preferred in enhancement of mechanical and fracture properties of plain concrete. It was previously shown that the higher fibre contents and fibre aspect ratios (the ratio of fibre length to diameter) increase the splitting tensile strength, flexural strength and fracture energy of conventionally vibrated fibre reinforced concrete (Eren \& Çelik 1997; Bayramov et al 2004). Therefore, a special design is needed to obtain self-compacting mixtures containing the required fibre content with sufficient flowability for the superior mechanical performance. It is well-known that beside the fibre type and content, the maximum aggregate size, total aggregate content and fine aggregate portion of the total aggregate are the key parameters in the design of steel fibre reinforced concrete (Swamy \& Mangat 1974; Swamy 1975; Bentur \& Mindess 1990; Johnston 1996). In case of the self-compacting concrete, the last two of these parameters may become more significant for a given fibre content, fibre type and maximum aggregate size. Although several mixture design approaches, which are mainly based on the optimization and the packing density of the granular skeleton of SFRSCC, have been introduced by several researchers (Ferrara et al 2007; Pereira et al 2013), there is no standardized and common mixture design method suggesting the appropriate fine and coarse aggregate portions for SFRSCC. Therefore more studies are needed.

This paper presents how the inclusion of steel fibres in different contents affects the flow characteristics, mechanical properties and fracture energies of SCC mixtures having similar paste volume but different FA/CA ratios. 


\section{Experimental program}

\subsection{Materials}

The cement used in all mixes was normal Portland cement corresponding to ASTM Type-I cement. C-type fly ash, obtained from Soma Power Plant/Turkey, was used as a powder type viscosity modifying material. Chemical and physical properties of cement and fly ash, provided by the suppliers, are given in table 1 . Crushed limestone fines $(0-3 \mathrm{~mm})$ and crushed limestone $(5-15 \mathrm{~mm})$ were used as fine aggregate (FA) and coarse aggregate (CA), respectively. Specific gravities and water absorption capacities of fine and coarse aggregates were 2.65, 1, 2.70 and $0.5 \%$, respectively. A modified polycarboxylate-based superplasticizer (SP) was used in all mixtures. Density and $\mathrm{pH}$ of the SP were $1076 \mathrm{~kg} / \mathrm{m}^{3}$ and 6.5 , respectively. Two types of hooked-end steel fibres (30 mm long and aspect ratio, $1 / \mathrm{d}=55$ and $60 \mathrm{~mm}$ long and $1 / \mathrm{d}=80$ ) were used.

\subsection{Mixture proportions}

Three self-compacting reference mixtures in different FA/CA ratios, namely A, B and C, were prepared by keeping the volume fractions of cement, fly ash, water and the total aggregate content as constant. Two types of hooked-end steel fibres $(1 / \mathrm{d}=55$ and 80$)$ were incorporated into the reference mixtures at three dosages $\left(20,40\right.$ and $\left.60 \mathrm{~kg} / \mathrm{m}^{3}\right)$. In fibered series, volume of the total aggregate was decreased by the same volume of the fibres by keeping the FA/CA ratio constant. Therefore, the total number of mixtures in the study is 21 consisting of three plain and 18 fibre incorporated mixtures.

Loose unit weight variation for different sand contents in total aggregate fraction was determined experimentally and the corresponding void contents in the total aggregate fraction were

Table 1. Chemical and physical properties of cement and fly ash.

\begin{tabular}{lccc}
\hline & & Cement & Fly ash \\
\hline $\mathrm{SiO}_{2}$ & $(\%)$ & 19.28 & 40.27 \\
$\mathrm{Al}_{2} \mathrm{O}_{3}$ & $(\%)$ & 5.30 & 19.56 \\
$\mathrm{Fe}_{2} \mathrm{O}_{3}$ & $(\%)$ & 2.05 & 4.08 \\
$\mathrm{CaO}$ & $(\%)$ & 63.08 & 28.59 \\
$\mathrm{MgO}$ & $(\%)$ & 0.98 & 1.57 \\
$\mathrm{SO}$ & $(\%)$ & 3.00 & 2.04 \\
$\mathrm{~K}_{2} \mathrm{O}$ & $(\%)$ & 0.90 & 1.38 \\
$\mathrm{Na}_{2} \mathrm{O}$ & $(\%)$ & 0.28 & 0.34 \\
$\mathrm{Free} \mathrm{CaO}_{\mathrm{L} o s s}$ on ignition & $(\%)$ & 1.45 & 8.77 \\
$\mathrm{Cl}$ & $(\%)$ & 2.81 & 1.33 \\
$\mathrm{Retaning}$ on $45 \mu$ sieve & $(\%)$ & 0.0032 & 0.0034 \\
$\mathrm{Retaining}$ on $90 \mu$ sieve & $(\%)$ & 15.60 & 37.90 \\
Specific gravity & $(\%)$ & 1.90 & 19.40 \\
Specific surface & $(-)$ & 3.11 & 2.20 \\
7-day compressive strength & $\left(\mathrm{m}^{2} / \mathrm{kg}\right)$ & 365.5 & 236.1 \\
28-day compressive strength & $(\mathrm{MPa})$ & 38.2 & - \\
Pozzolanic activity* (7 days) & $(\mathrm{MPa})$ & 48.5 & - \\
Pozzolanic activity* (28 days) & $(\%)$ & - & 72.10 \\
\hline
\end{tabular}

* According to TS EN 450 
calculated based on the formula given by Gomes (2002) and presented in figure 1a. The FA/CA ratio, providing the maximum loose unit weight and the corresponding minimum void content in the aggregate phase, was determined under a chosen powder content of $580 \mathrm{~kg} / \mathrm{m}^{3}$. The chosen powder content meets the recommended limits $\left(400\right.$ to $600 \mathrm{~kg} / \mathrm{m}^{3}$ ) given by EFNARC (2002) and consists of $400 \mathrm{~kg} / \mathrm{m}^{3}$ cement and $180 \mathrm{~kg} / \mathrm{m}^{3}$ fly ash. Water content is also selected $180 \mathrm{~kg} / \mathrm{m}^{3}$ to meet the recommended water to powder content limits for SCC ( 0.80 to 1.1 by volume) given in EFNARC (2002).

A target slump-flow value of $750 \pm 20 \mathrm{~mm}$ was chosen and the required SP dosage was arranged to obtain the target flowability without any segregation. In order to set the limits of the FA/CA ratios that can be used for the chosen powder content, a series of trial mixtures were prepared and FA/CA ratio of 0.94 and 2.50 were found suitable limits for the appropriate flowability and passing ability. It was observed that the mixtures having FA/CA ratios lower than 0.94 showed poor flowability and high blocking tendency in L-box test while the FA/CA ratios higher than 2.50 are required in excessive amount of SP to obtain a flowable mixture. Particle size distribution of the mixtures is shown in figure 1b. Plain (reference) SCC mixture proportions and the type and the amount of the fibres used are given in tables 2 and 3, respectively. The abbreviations $\mathrm{A} 00, \mathrm{~B} 00$ and $\mathrm{C} 00$ are used for the plain mixtures having FA/CA ratio of $0.94,1.72$ and 2.50, respectively. The first and the second numbers in the abbreviations show the fibre type

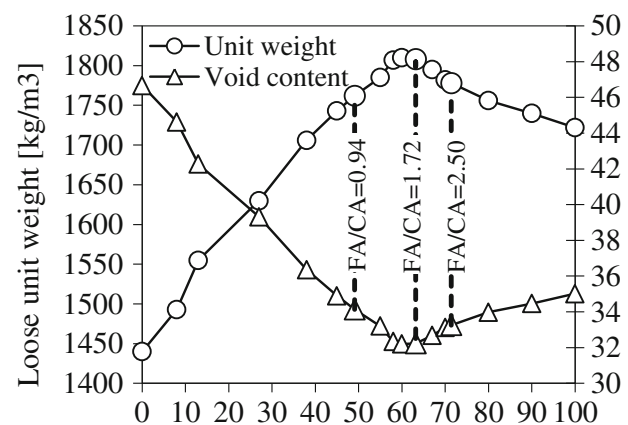

Fine to total aggregate by weight $(\%)$

(a)

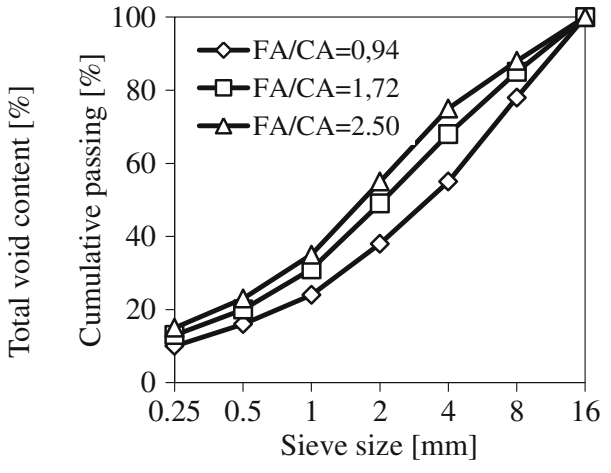

(b)

Figure 1. Loose unit weight and total void content variation of different fine and coarse aggregate ratios (a) and particle size distribution of selected aggregate ratios (b).

Table 2. Mixture proportions of reference (plain) self-compacting concretes.

\begin{tabular}{lccc}
\hline Component $\left(\mathrm{kg} / \mathrm{m}^{\mathbf{3}}\right)$ & A00 & B00 & C00 \\
\hline Cement & 403 & 399 & 395 \\
Fly ash & 181 & 179 & 178 \\
Water & 187 & 184 & 183 \\
Fine aggregate (FA) & 764 & 984 & 1099 \\
Coarse aggregate (CA) & 816 & 572 & 439 \\
Superplasticizer & 5.4 & 6.1 & 6.5 \\
Measured air $(\%)$ & 0.6 & 1.7 & 2.6 \\
FA/CA (by weight) & 0.94 & 1.72 & 2.50 \\
Fine to total aggregate by weight $(\%)$ & 48.4 & 63.2 & 71.5 \\
\hline
\end{tabular}


Table 3. Test results on fresh concretes.

\begin{tabular}{|c|c|c|c|c|c|c|c|c|}
\hline \multicolumn{4}{|c|}{ Mixture properties } & \multirow[b]{2}{*}{$\begin{array}{c}\text { Flow } \\
\text { diameter }\end{array}$} & \multirow[b]{2}{*}{$\begin{array}{c}\text { Decrease } \\
\text { in flow } \\
\text { diameter }(\%)\end{array}$} & \multirow[b]{2}{*}{$\begin{array}{l}\mathrm{T}_{50} \\
(\mathrm{~s})\end{array}$} & \multirow[b]{2}{*}{$\begin{array}{l}\text { J-ring } \\
(\mathrm{mm})\end{array}$} & \multirow[b]{2}{*}{$\begin{array}{l}\text { Blocking } \\
\text { ratio } \\
\left(\mathrm{H}_{2} / \mathrm{H}_{1}\right)\end{array}$} \\
\hline $\begin{array}{l}\text { Mixture } \\
\text { ID }\end{array}$ & $\begin{array}{c}\mathrm{FA} / \mathrm{CA} \\
\text { ratio }\end{array}$ & $\begin{array}{c}\text { Fiber } \\
\text { aspect } \\
\text { ratio }\end{array}$ & $\begin{array}{c}\text { Fibre } \\
\text { content } \\
\left(\mathrm{kg} / \mathrm{m}^{3}\right)\end{array}$ & & & & & \\
\hline A00 & 0.94 & - & 0 & 765 & - & 3.0 & 5 & 0.87 \\
\hline A11 & 0.94 & $55^{*}$ & 20 & 750 & 2.0 & 3.3 & 5 & 0.82 \\
\hline A12 & 0.94 & 55 & 40 & 690 & 9.8 & 3.5 & 8 & 0.70 \\
\hline A13 & 0.94 & 55 & 60 & 600 & 21.6 & 4.0 & 11 & 0.45 \\
\hline A21 & 0.94 & $80^{* *}$ & 20 & 720 & 5.9 & 3.5 & 8 & 0.66 \\
\hline A22 & 0.94 & 80 & 40 & 635 & 17.0 & 4.1 & 9 & 0 (Blocking) \\
\hline A23 & 0.94 & 80 & 60 & 530 & 30.7 & 4.0 & 14 & 0 (Blocking) \\
\hline B00 & 1.72 & - & 0 & 775 & - & 2.5 & 4 & 0.90 \\
\hline B11 & 1.72 & 55 & 20 & 755 & 2.6 & 3.0 & 5 & 0.88 \\
\hline B12 & 1.72 & 55 & 40 & 710 & 8.4 & 3.7 & 8 & 0.83 \\
\hline B13 & 1.72 & 55 & 60 & 640 & 17.4 & 4.0 & 9 & 0.70 \\
\hline B21 & 1.72 & 80 & 20 & 750 & 3.2 & 3.2 & 7 & 0.85 \\
\hline B22 & 1.72 & 80 & 40 & 700 & 9.7 & 3.5 & 7 & 0.76 \\
\hline B23 & 1.72 & 80 & 60 & 600 & 22.6 & 4.5 & 9 & 0.40 \\
\hline $\mathrm{C} 00$ & 2.50 & - & 0 & 780 & - & 2.8 & 4 & 0.95 \\
\hline C11 & 2.50 & 55 & 20 & 765 & 1,9 & 3.0 & 5 & 0.92 \\
\hline C12 & 2.50 & 55 & 40 & 720 & 7,7 & 3.0 & 6 & 0.88 \\
\hline $\mathrm{C} 13$ & 2.50 & 55 & 60 & 680 & 12,8 & 3.8 & 6 & 0.84 \\
\hline $\mathrm{C} 21$ & 2.50 & 80 & 20 & 760 & 2,6 & 3.0 & 5 & 0.92 \\
\hline $\mathrm{C} 22$ & 2.50 & 80 & 40 & 720 & 7,7 & 3.6 & 7 & 0.86 \\
\hline $\mathrm{C} 23$ & 2.50 & 80 & 60 & 660 & 15,4 & 4.2 & 10 & 0.81 \\
\hline
\end{tabular}

* Fibre length $1=30 \mathrm{~mm}$, hooked-end steel fibres.

** Fibre length $1=60 \mathrm{~mm}$, hooked-end steel fibres.

(0: no fibre, $1: 1 / \mathrm{d}=55$ fibres, $2: 1 / \mathrm{d}=80$ fibres) and the fibre content ( $0:$ no fibre, $1: 20 \mathrm{~kg} / \mathrm{m}^{3}$, 2: $\left.40 \mathrm{~kg} / \mathrm{m}^{3}, 3: 60 \mathrm{~kg} / \mathrm{m}^{3}\right)$. In this coding system, for example, B21 shows the mixture having FA/CA ratio of 1.72 and reinforced with $1 / \mathrm{d}=80$ fibres in the dosage of $20 \mathrm{~kg} / \mathrm{m}^{3}$.

\subsection{Test procedures on fresh and hardened concretes}

Self-compactibility characteristics of the mixtures were assessed with slump-flow with J-ring for restricted flowability and L-box tests for passing ability. Test apparatuses are shown in figures $2 \mathrm{a}$ and $b$. The detailed procedures of slump-flow and L-box tests are not described here but can be found in EFNARC (2002). The slump flow diameter is considered as the average diameter of the two perpendicular directions. During slump-flow test, the time taken by the concrete to reach the $500 \mathrm{~mm}$ spread circle was measured by a stopwatch and recorded as $\mathrm{T}_{50}$. Passing ability of the mixture was assessed with J-ring measurements and L-box tests. The difference in height between the concrete just inside the J-ring bars and that just outside the bars was measured in $\mathrm{mm}$. In L-box test, $3 \times 12 \phi$ smooth bar arrangement with an opening gap of $41 \mathrm{~mm}$ between the bars was used for plain SCC mixtures as recommended in EFNARC (2005) (figure 2b). Since a $41 \mathrm{~mm}$ opening gap is not appropriate to assess the passing ability of 30 or $60 \mathrm{~mm}$ long steel fibre incorporated series, two of three $12 \phi$ bars were removed and only one centered bar was used in front of the door of L-box apparatus in SFRSCC mixtures. By this modification in L-box 


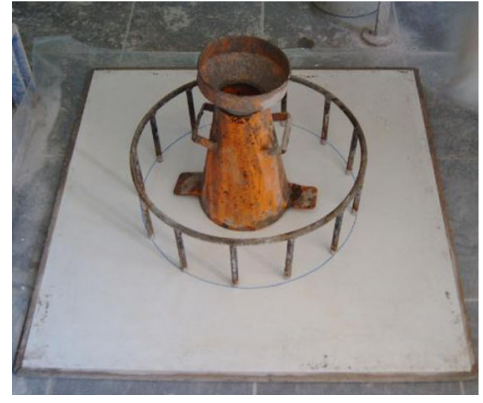

(a)

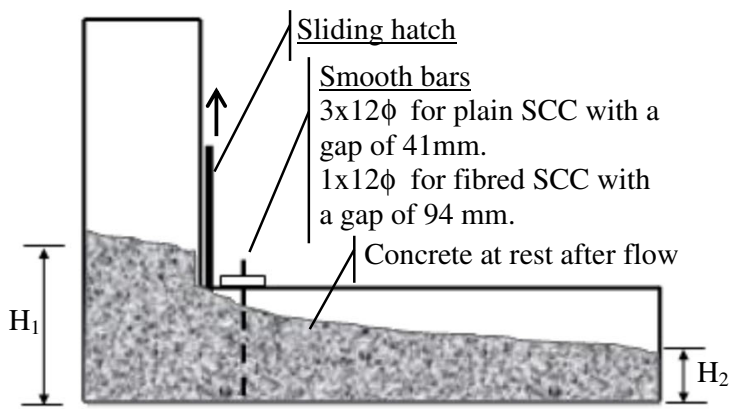

(b)

Figure 2. Slump-flow with J-ring (a), illustration of L-box apparatus (b).

apparatus, the opening gap was increased to $94 \mathrm{~mm}$ for SFRSCC mixtures (figure 2b). Different bar spacing to assess the passing ability of fibre reinforced mixtures with different types and contents was also suggested by Grünewald \& Walraven (2001) previously. When the flow has stopped, the mean height of the concrete at the end of the horizontal section $\left(\mathrm{H}_{2}\right)$ and the average height of concrete remained in the vertical section $\left(\mathrm{H}_{1}\right)$ were measured as illustrated in figure $2 \mathrm{~b}$. The passing ability of concrete is considered as the slope of the concrete at rest after flow $\left(\mathrm{H}_{2} / \mathrm{H}_{1}\right.$ ratio) in L-box apparatus.

Uniaxial compressive strength and flexural tests were carried out on $\phi 100 \times 200 \mathrm{~mm}$ cylindrical and $100 \times 100 \times 500 \mathrm{~mm}$ prismatic samples, respectively. Three samples from each fresh mixture were taken without any vibration or compaction energy and the average values obtained from these samples were presented for each mixture. Flexural strength and fracture energy was determined by three point bending test on notched beams according to the procedure given by RILEM 1985. Notch was prepared by a diamond-saw as being the notch to depth ratio of 0.40 . Hillerborg (1983) states that a notch depth of at least 0.3-0.4 times the beam depth is enough to minimize irreversible deformations outside the fracture zone in three-point bending test for the determination of fracture energy. This notch depth is also suitable to accommodate the coarse aggregates and the steel fibres used. Bayramov et al (2004) has been used the same notch to depth ratio for the determination of fracture energy of steel fibre reinforced concretes. Three point bending test was carried out with a closed-loop testing machine and mid-span deflection data was used as a feedback during the test. Fracture energy $\left(\mathrm{G}_{\mathrm{F}}\right)$ is defined as the amount of energy necessary to create one unit area of a crack (RILEM 1985). The area under load-mid-span deflection curves were used for evaluating the fracture energy $\left(\mathrm{G}_{\mathrm{F}}\right)$ of plain and fibred concrete. Complete load-deflection curve until the beam was broken into two halves was obtained for plain beams. For fibered series, the load-deflection curve was used up to a specified deflection of $5 \mathrm{~mm}$ as a cut-off point for the calculations. Similar approach has been applied to calculate the $\mathrm{G}_{\mathrm{F}}$ by Bayramov et al (2004). Flexural strength $\left(\mathrm{f}_{\text {flex }}\right)$ and fracture energy $\left(\mathrm{G}_{\mathrm{F}}\right)$ of notched beams subjected to three-point loading were calculated according to Eqs. (1) and (2), respectively.

$$
f_{\text {flex }}=\frac{3 P S}{2 b(h-a)^{2}},
$$


where, P, S, b, h, a are ultimate load, span length, beam width, height and notched depth, respectively.

$$
G_{F}=\frac{W+m g \frac{S}{L} \delta}{b(h-a)},
$$

where, W, m, $g, \mathrm{~L}, \delta$ are area under the load-deflection curve, weight of the beam, gravitational acceleration, length of the beam and the deflection of the beam ( $5 \mathrm{~mm}$ for fibred series), respectively. Eq. (2) contains the fracture energy supplied by beam weight.

\section{Experimental results}

\subsection{Test results on fresh concrete}

Table 3 shows all the results on fresh concrete and figure 3 shows the effect of FA/CA ratio and fibre content on slump-flow diameter of the series containing the aspect ratio of 55 and 80 fibres. All plain mixtures satisfied the self-compactibility limits suggested by EFNARC (2002) and a slight increase was observed in flow diameter with increasing FA/CA ratio. On the other hand, increasing fibre content resulted in a decrease in flow diameter for all fibred series. Mixtures having FA/CA ratio of 0.94 were the mixtures that have been affected the most from fibre inclusion among all mixtures. As can be seen from figure 3, the higher the aspect ratio the lower is the slump-flow diameter for a given fibre content. As presented in table 3, increasing the FA/CA ratio from 0.94 to 2.50 , by keeping the similar paste volume, considerably decreased to the extent of the decrease in slump-flow diameter due to the fibre inclusion for both fibre types. In SFRSCC mixtures containing $1 / \mathrm{d}=55$ fibers in $60 \mathrm{~kg} / \mathrm{m}^{3}$ dosage, the decrease in slump-flow diameter due to fibre inclusion is $21.6 \%$ when the FA/CA ratio of the mixture is 0.94 . This decrease in slump-flow diameter could be lowered to 17.4 and $12.8 \%$ if the FA/CA ratio of the mixture is increased to 1.72 and 2.50, respectively. Similarly, the decrease of $30.7 \%$ in slump-flow diameter in SFRSCC mixtures containing $1 / \mathrm{d}=80$ fibres in $60 \mathrm{~kg} / \mathrm{m} 3$ dosage could be lowered to 22.6 and $15.4 \%$ by increasing FA/CA ratio of mixture to 1.72 and 2.50 , respectively as seen in table 3 .

As a general trend, non-homogeneous flow spreads were observed in the mixtures containing $1 / \mathrm{d}=80$ fibres in $60 \mathrm{~kg} / \mathrm{m}^{3}$ dosage. Similar findings were also reported by Grünewald \& Walraven (2001) for longer steel fibres. It should be noted that aggregate and fibre segregation at the centre of the flow spread was also observed in series with FA/CA $=0.94$ containing $60 \mathrm{~kg} / \mathrm{m}^{3}$
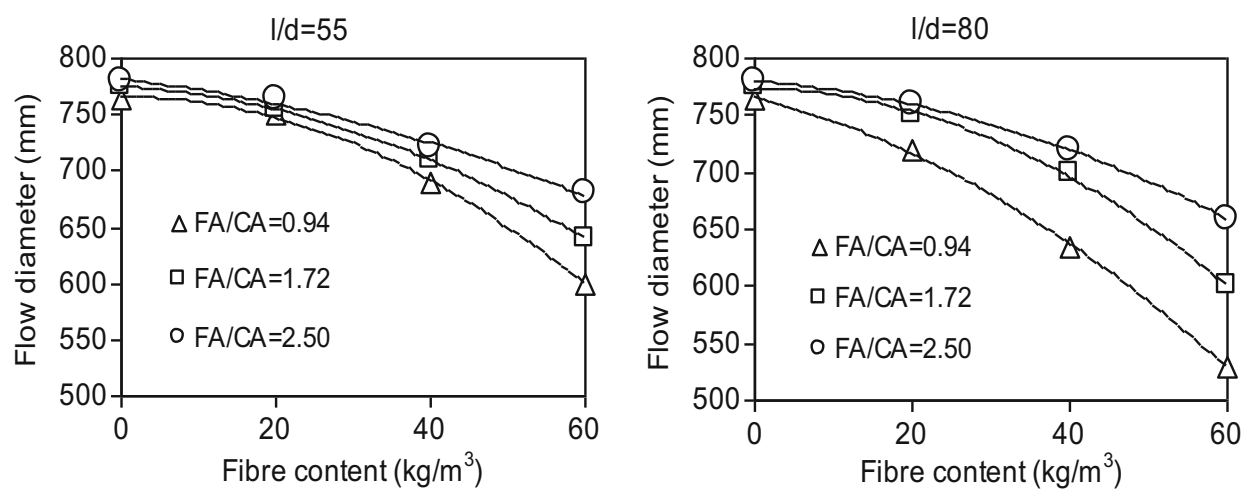

Figure 3. Effects of the FA/CA ratio and fibre content on flow diameter. 
of long fibres (figure 4a). This problem diminished by increasing the FA/CA ratio (figure $4 \mathrm{~b}$ ). In addition, J-ring test results showed that when the fibre content exceeds $40 \mathrm{~kg} / \mathrm{m}^{3}$, blocking tendency was observed in the mixtures with high J-ring values in comparison with plain reference mixture (table 3).

Figure 5 shows the effect of FA/CA ratio and fibre content on the $\mathrm{H}_{2} / \mathrm{H}_{1}$ ratio in L-box test. The test is recommended to assess the passing ability of the mixture. Increasing $\mathrm{H}_{2} / \mathrm{H}_{1}$ ratio indicates the good passing ability as described in EFNARC (2002). For a given FA/CA ratio, increasing the fibre content decreased the $\mathrm{H}_{2} / \mathrm{H}_{1}$ ratio for both types of fibres. However, blocking tendency was more pronounced for longer fibres. According to L-box test results, it was obvious that increasing the FA/CA ratio decreased the blocking risk and enhanced the passing ability of SFRSCC for a given fibre content. Obvious blocking of coarse aggregate and fibres behind the reinforcing bar was detected visually in the series having $\mathrm{H}_{2} / \mathrm{H}_{1}$ ratio of 0.60 . Beyond this limit there was no blocking tendency of coarse aggregates and fibres. It could be deduced from the experiments that the inclusion of high aspect ratio fibres even at very low dosage (i.e., $20 \mathrm{~kg} / \mathrm{m}^{3}$ ) can cause a significant blocking tendency.

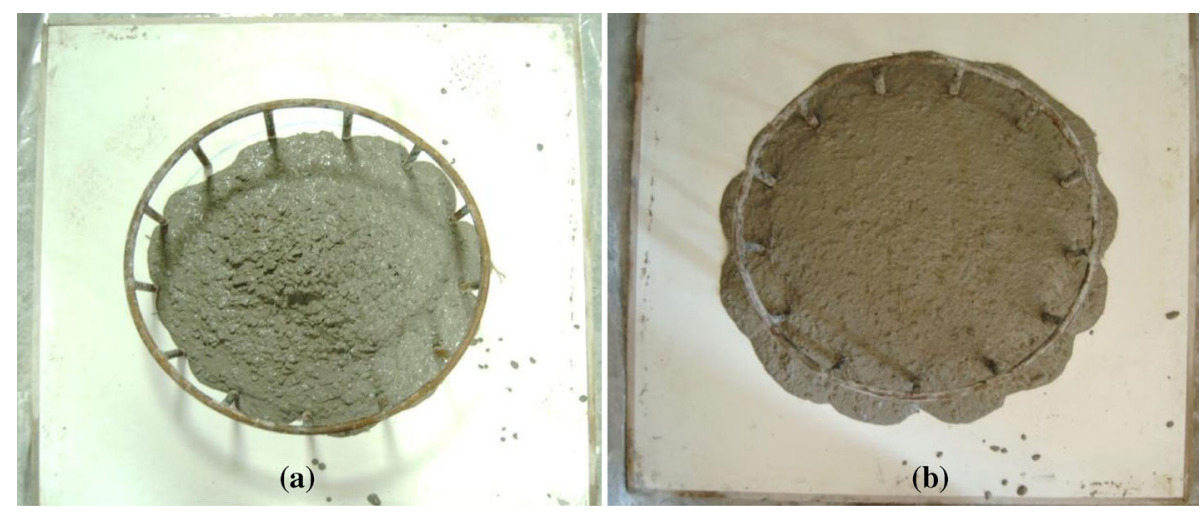

Figure 4. Slump-flow appearance of SFRSCC mixtures having $1 / \mathrm{d}=80$ fibers in $60 \mathrm{~kg} / \mathrm{m}^{3}$ dosage when FA/CA is 0.94 (a) and 2.50 (b).
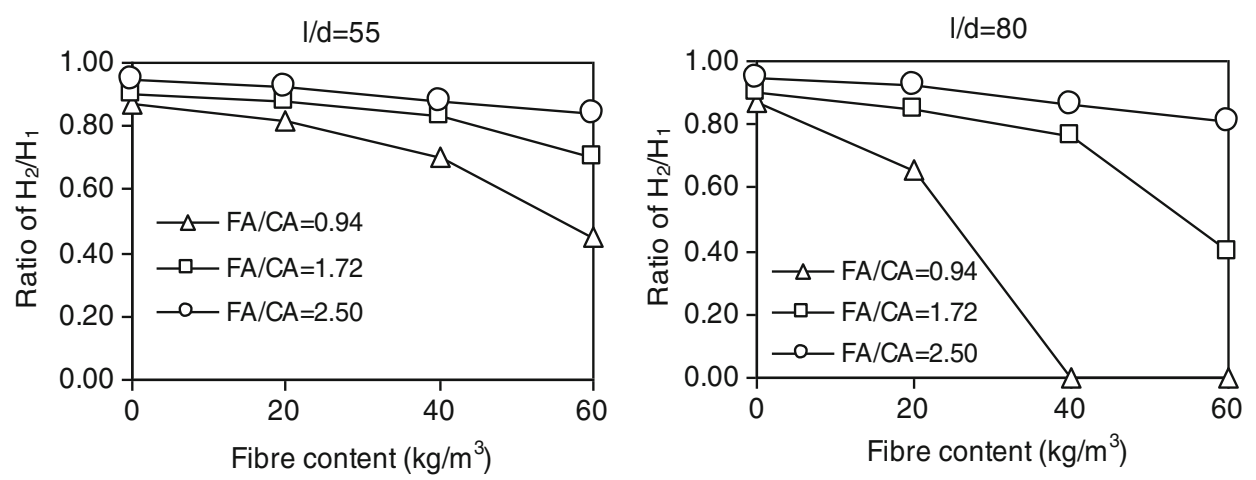

Figure 5. Effect of the FA/CA ratio and fibre content on $\mathrm{H}_{2} / \mathrm{H}_{1}$ ratio. 


\subsection{Test results on hardened concrete}

3.2a Compressive strength: Uniaxial compressive test was carried out at the age of 28 days. As seen in table 4, an increase in FA/CA ratio from 0.94 to 2.50 resulted in a decrease of $13.7 \%$ in the compressive strength of plain SCC. One possible explanation for this can be following: Increasing the fine aggregate content increases the specific surface area of the aggregates as well as the amount of fine $(<0.15 \mathrm{~mm})$ and very fine $(<0.075 \mathrm{~mm})$ particles. This increases water demand to wet the surface of fine particles and the required amount of cement paste to coat all aggregates. It was previously reported that the increase in specific surface area of the fine aggregates leads to decrease in slump-flow and the compressive strength of SCC due to insufficient cement paste to coat all fine aggregates if the cement, water and the superplasticizer contents are kept constant (Benabed et al 2012). In the present study, the polycarboxylate-based superplasticizer content was increased to balance the expected decrease in flowability as the FA/CA ratio increases (table 2). By this way, the flowability could be maintained (table 3), but a considerable increase in air content $(0.6 \%$ vs. $2.7 \%)$ and a decrease in compressive strength by $13.7 \%$ were observed. This probably indicates that the available paste content may not be entirely enough to coat all fines even in highly flowable SCC mixtures. The increase in air content may be attributed to the uncoated fines leading to increase the amount of entrapped air which consequently leads to decrease in compressive strength (Neville 1995).

Compressive strengths of SFRSCC mixtures having different FA/CA ratios is shown in figure 6a. As a general trend, increasing the fibre content resulted in a decrease in compressive strength of SFRSCC in the present study. In the literature there are contradicting results on the effect of steel fibres on the compressive strength of self-compacting concretes. Khaloo et al (2014) reported that compressive strength decreases by increasing the percentages of hookedend steel fibres. On the contrary, Pajak \& Ponikiewsky (2013) reported that the addition of randomly distributed short steel fibres increases the compressive strengths of SCC. This shows that the effect of steel fibres on the compressive strength of self-compacting concrete depends on how the steel fibres affect the workability of concrete and the mixture properties of SCCs have a significant effect as well as the fibre properties.

As a general trend, fibre inclusion to plain SCC negatively affects the flow properties of steel fibre reinforced self-compacting concretes and the FA/CA ratio of the mixture enhances the workability of SFRSCC mixtures. In the low fibre contents such as $20 \mathrm{~kg} / \mathrm{m}^{3}$, flow properties are less affected from the fibre inclusion (figure 3 ) and hence, the mixture with FA/CA ratio of 0.94 at this fibre dosage presents high flowability (A11 mixture in table 3 ). Therefore, the maximum compressive strength at this dosage $\left(20 \mathrm{~kg} / \mathrm{m}^{3}\right)$ was obtained in the series having FA/CA ratio of 0.94 as in the case of plain SCC. However, when the fibre content was increased to $40 \mathrm{~kg} / \mathrm{m}^{3}$ slump-flow of the series having FA/CA ratio of 0.94 significantly decreased compared to series having FA/CA ratio of 1.72 , therefore the maximum compressive strength was obtained in this series. Further increase in FA/CA ratio of the mixture at this fibre dosage did not

Table 4. Mechanical properties of reference SCC mixtures without fibres (values in parenthesis represent standard deviation for three samples).

\begin{tabular}{lccc}
\hline Mechanical property & FA/CA $=0.94$ & FA/CA $=1.72$ & FA/CA $=2.50$ \\
\hline Compressive strength $(\mathrm{MPa})$ & $73.3(3.4)$ & $65.1(1.9)$ & $63.4(2.0)$ \\
Flexural strength $(\mathrm{MPa})$ & $5.2(0.2)$ & $5.1(0.2)$ & $4.8(0.2)$ \\
Fracture energy $(\mathrm{N} / \mathrm{m})$ & $76(2.8)$ & $51(4.1)$ & $47(1.3)$ \\
\hline
\end{tabular}




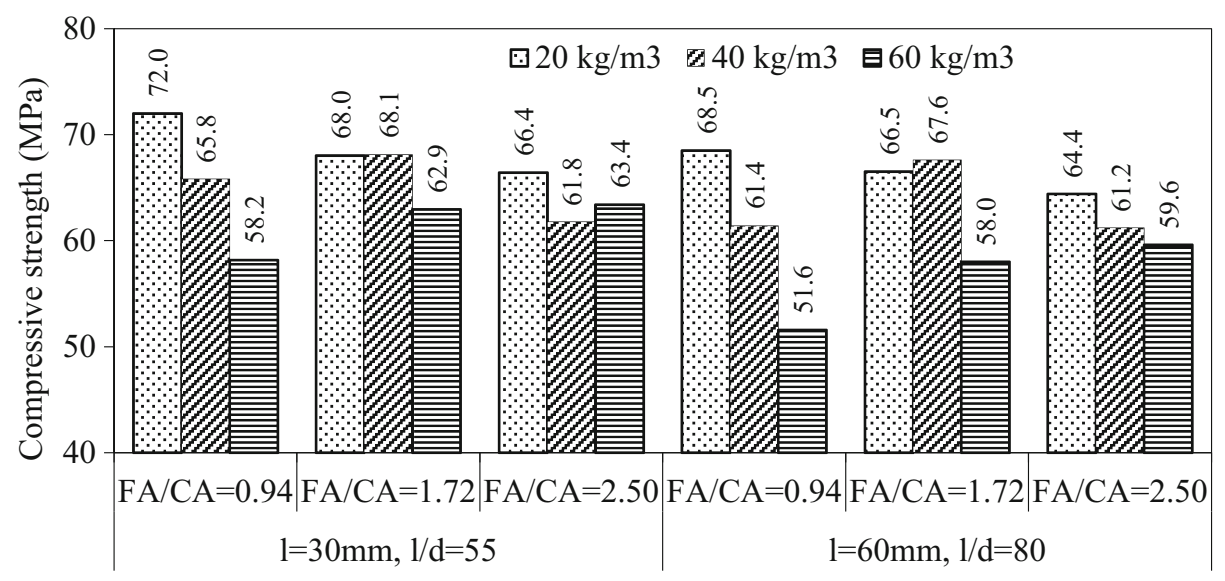

(a)

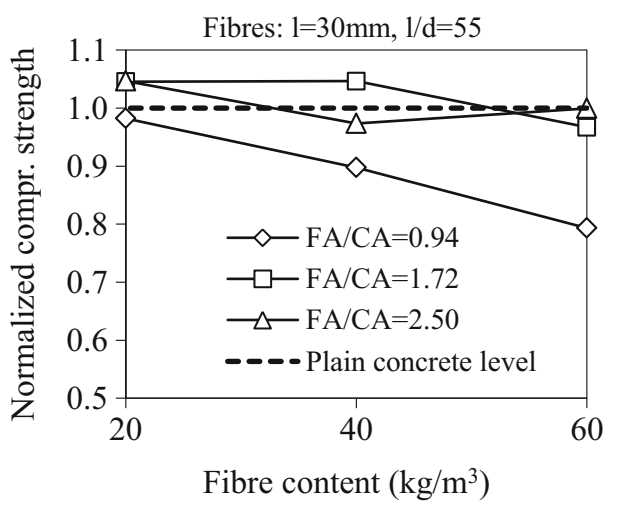

(b)

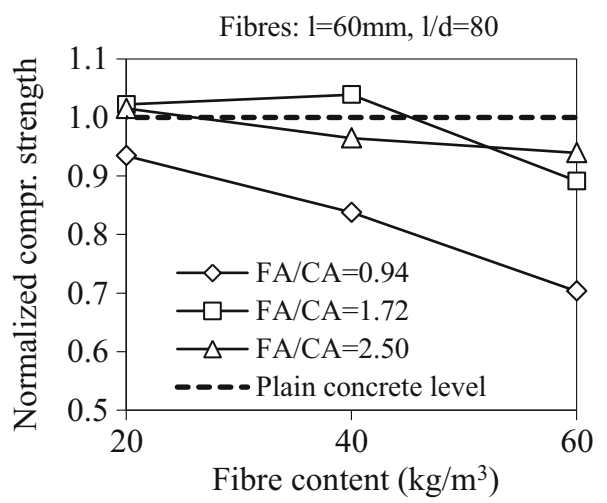

(c)

Figure 6. Effect of fibre content and FA/CA ratio on the compressive strength of SFRSCC mixtures (a), and the effectiveness of $1 / d=55$ (b) and $1 / d=80$ (c) fibres on the enhancement of compressive strength of plain SCC mixtures in different FA/CA ratios.

lead to compressive strength increase. This shows that increasing FA/CA ratio of a fibre incorporated mixture, which is already sufficiently flowable, may decrease the compressive strength. However, increasing FA/CA ratio of the mixture which is significantly affected from the fibre inclusion enhances both workability and the mechanical properties. This could be observed in the mixtures reinforced with steel fibres in the dosage of $60 \mathrm{~kg} / \mathrm{m}^{3}$. As can be seen from figure 3 , increasing FA/CA ratio of the mixture at this fibre dosage enhanced workability of the fibered mixture and also the compressive strength.

Figures $6 b$ and $c$ show the effect of $1 / d=55$ and $1 / d=80$ fibre inclusion on the enhancement of compressive strength of plain SCC mixtures in different FA/CA ratios, respectively. It can be seen from figures $6 \mathrm{a}$ and $\mathrm{b}$ that, fibre inclusion to plain concrete leads to a considerable compressive strength loss compared to plain concrete strength level when the low FA/CA ratio was used. However, this trend was not the same for the series having relatively high FA/CA ratios. The alteration in compressive strength due to the fibre inclusion was $10 \%$ or less in the mixtures with FA/CA ratios of 1.72 and 2.50. It was also previously reported that the fibres in normally 
vibrated conventional fibre reinforced concrete have minimal effect on compressive strength (Bayramov et al 2004; Shah et al 1978; Chen \& Liu 2004) even in normal and high strength concrete cases (Thomas \& Ramaswamy 2007). However, as can be seen from figures $6 \mathrm{~b}$ and c the effect of fibres on compressive strength is considerable when coarser grading (low FA/CA ratio) was used in SFRSCC.

3.2b Flexural performance and fracture energy: Bending load vs. mid-span deflection curves obtained from plain SCC mixtures having different FA/CA ratios are shown in figure 7. As observed in figure 7, the slope of descending part of the curve became steeper and shorter as the FA/CA ratio increases from 0.94 to 1.72. A further increase in FA/CA ratio from 1.72 to 2.50 did not significantly affect the slope of the descending part of the curve. Steep and shorter descending part of load-deflection curve may be attributed to consuming less energy during fracture when relatively higher FA/CA ratio was used. Considering the result presented here (table 4), it can be concluded that fracture energy of plain SCC decreases as the FA/CA ratio increases. Increasing FA/CA ratio from 0.94 to 1.72 resulted in a decrease of $30 \%$ in fracture energy of plain SCC. The decrease in fracture energy was $8 \%$ when FA/CA ratio increased from 1.72 to 2.50. The effect of the maximum aggregate size and coarse aggregate fraction of total aggregate volume on the fracture behavior of concrete has been pointed out by other researchers (Wittmann 2002; Appa Rao \& Raghu Prasad 2002; Chen \& Liu 2004). Chen \& Liu (2004) showed that increasing the coarse aggregate volume fraction from 40 to $60 \%$ by keeping the total aggregate content constant results in an increase in fracture energy, and then a decrease as the volume fraction of coarse aggregate continues to increase from 60 to $80 \%$. Although the results presented by Chen \& Liu (2004) belong to normally vibrated high strength concretes, the results coincide with the result of the study presented here for SCC as relatively low FA/CA ratio addresses high volume fraction of coarse aggregate.

Typical load-mid-span deflection curves and flexural strengths of SFRSCC samples having different FA/CA ratios are shown in figures 8 and 9a, respectively. Figure 8 clearly shows the reinforcing effect of the fibres and the enhancement in the post-peak performance of concrete by

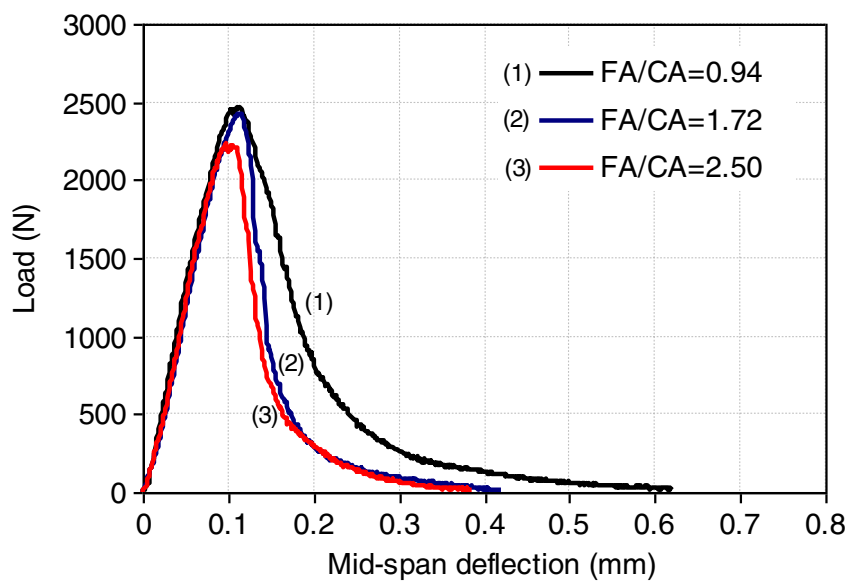

Figure 7. Load vs. mid-span deflection curves of SCCs having different FA/CA ratios (curves represent the average of three curves for each FA/CA series). 

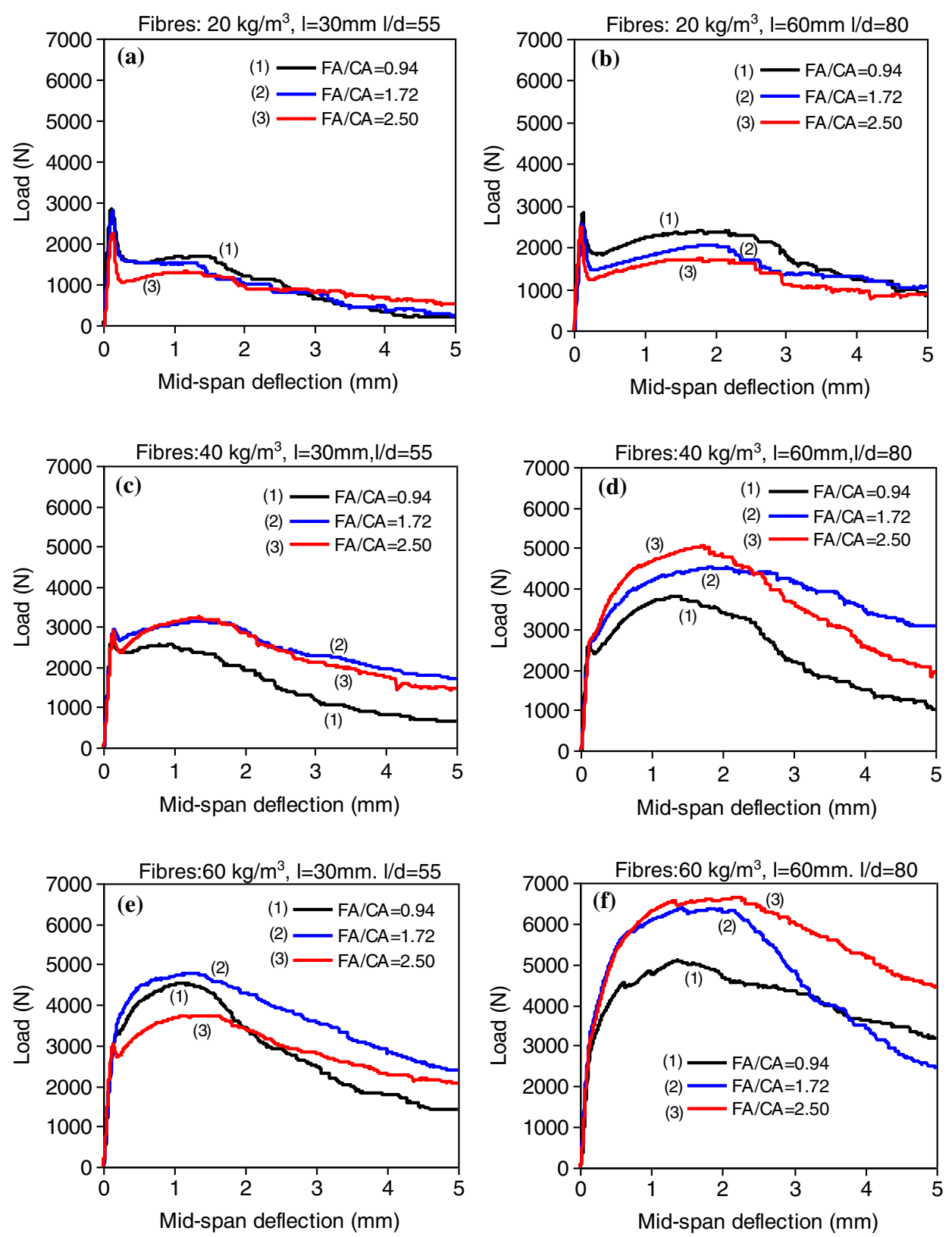

Figure 8. Typical load-mid-span deflection curves of SFRSCCs having different FA/CA ratios (each curve is the average of the three curves of the relevant mixture).

fibre inclusion. The bending behaviour of fibre reinforced cementitious composites can be classified as deflection-softening or deflection-hardening generating a higher load carrying capacity after first cracking compared with normal concrete or deflection-softening fibre reinforced composite (Naaman \& Reinhardt 2006). The first cracking point can be defined as the point 


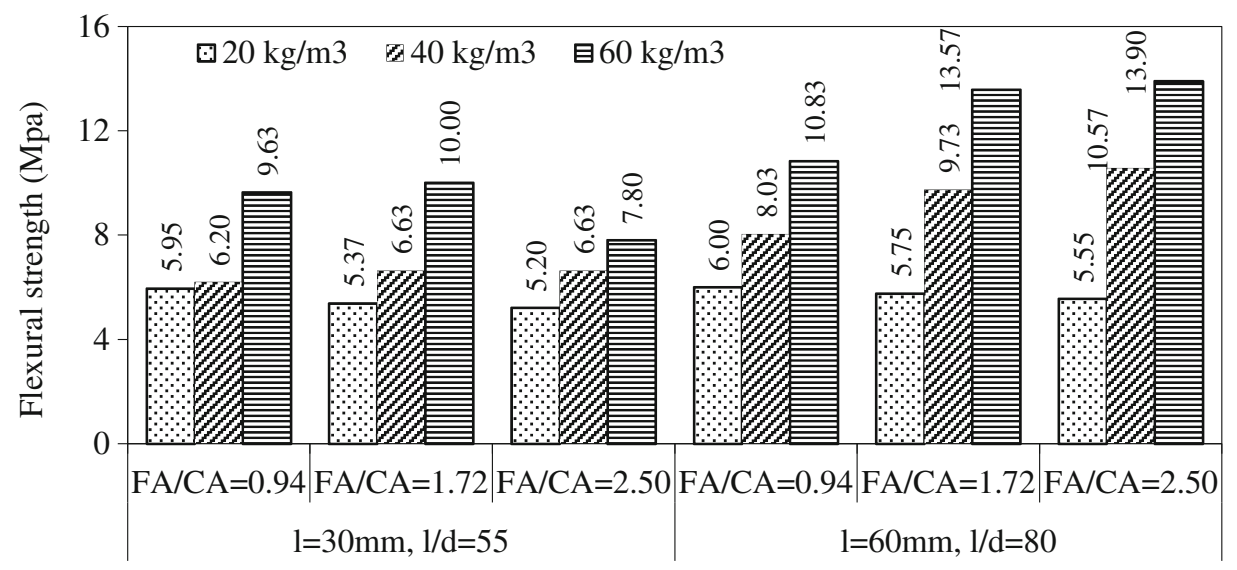

(a)

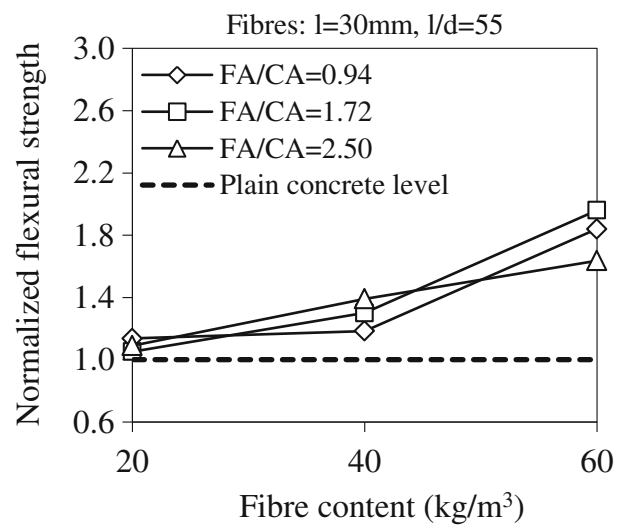

(b)

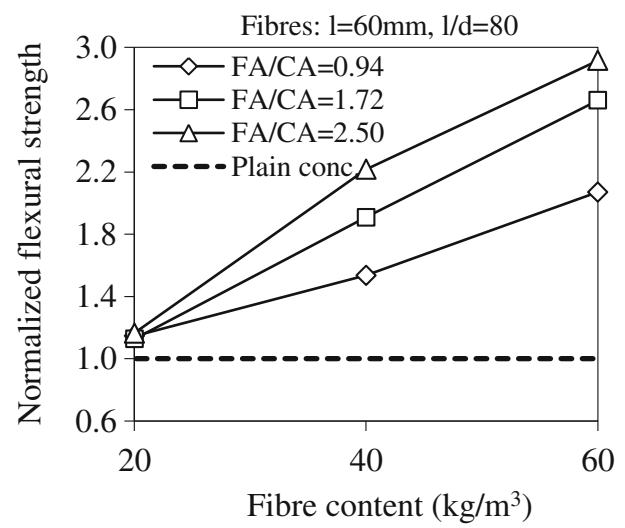

(c)

Figure 9. Effect of fibre content and FA/CA ratio on the flexural strength of SFRSCC mixtures (a), the effectiveness of $1 / d=55$ (b) and $1 / d=80$ (c) fibres on the enhancement of flexural strength of plain SCC mixtures in different $\mathrm{FA} / \mathrm{CA}$ ratios.

where nonlinearity in the load-deflection curve becomes evident (Kim et al 2008). In this study, a deflection hardening response was observed after the first crack deflection, in the specimens reinforced with low aspect ratio $(1 / \mathrm{d}=55)$ fibres in $60 \mathrm{~kg} / \mathrm{m}^{3}$ dosage (figure $8 \mathrm{e}$ ) and high aspect ratio $(1 / \mathrm{d}=80)$ fibres in 40 and $60 \mathrm{~kg} / \mathrm{m}^{3}$ dosages (figure $8 \mathrm{~d}$ and $\mathrm{f}$ ). This shows the more effective reinforcing effect of high aspect ratio hooked-end steel fibres. Similar results have been presented by Pajak \& Ponikiewsky (2013) for self-compacting concrete reinforced with hookedend steel fibres. FA/CA ratio, fibre content and aspect ratio have a considerable effect on flexural strength of fibred SCC as can be seen in figure 9a. As shown in figure, flexural strength clearly increased as the fibre content increased. As a general trend, the higher flexural strength values were obtained in the series having higher aspect ratio fibres. This is more distinct when the fibre contents are 40 and $60 \mathrm{~kg} / \mathrm{m}^{3}$. The fibres having higher aspect ratio were found to be more effective in improving the post-peak performance of SFRSCC as parallel to the results presented for 
conventionally vibrated fibre reinforced concretes (Bayramov et al 2004; Eren \& Çelik 1997; ACI 544.1R-96 1997).

When the fibre content was relatively low $\left(20 \mathrm{~kg} / \mathrm{m}^{3}\right)$, increasing the $\mathrm{FA} / \mathrm{CA}$ ratio has resulted with a slight flexural strength decrement as parallel to the plain SCC results (table 4). On the other hand, flexural strength decrement trend against the FA/CA ratio increment was reversed for the series having fibre contents of 40 and $60 \mathrm{~kg} / \mathrm{m}^{3}$ with one exceptional case. Increasing the FA/CA ratio increased the flexural strength at the fibre dosage of $40 \mathrm{~kg} / \mathrm{m}^{3}$. However, as an exceptional case in lower aspect ratio series, increasing the FA/CA ratio from 1.72 to 2.50 has resulted in a considerable flexural strength decrement for $60 \mathrm{~kg} / \mathrm{m}^{3}$ fibre content.

Figures $9 \mathrm{~b}$ and c clearly show the effect of $1 / \mathrm{d}=55$ and $1 / \mathrm{d}=80$ fibre inclusions on the enhancement of flexural strength of plain SCC mixtures in different FA/CA ratios, respectively. It is obvious that the fibre inclusion to plain SCC considerably enhanced the flexural strength capacity of concrete. However, the performance of the fibres was not the same for a given fibre content. The maximum fibre performance for the enhancement of the flexural strength of plain SCC was obtained in the series having relatively high FA/CA ratios particularly when the 1/d = 85 fibres were used. In other words, increasing the FA/CA ratio increased the contribution of fibre performance to the enhancement the flexural strength capacity of concrete.

As shown in table 4, fracture energy of plain SCC mixture decreases with an increase in FA/CA ratio. It was found that increasing the FA/CA ratio from 0.94 to 2.50 can result in a considerable fracture energy decrement of $38 \%$ for plain SCC. This finding reveals the significant effect of the FA/CA ratio on the fracture behaviour of SCC mixture. For plain SCC mixtures, the maximum fracture energy was obtained when the coarse aggregate volume fraction of the total aggregate was high however; this trend was not the same for SFRSCC containing upon the fibre content of $20 \mathrm{~kg} / \mathrm{m}^{3}$ (figure 10a).

As can be seen in figure 10a, fracture energy decreased with increasing the FA/CA ratio as parallel to plain SCC trend when the fibre content was relatively low as $20 \mathrm{~kg} / \mathrm{m}^{3}$. However, it was found that, the relatively fine grading should be used to obtain high level of fracture energy when the fibre contents were 40 and $60 \mathrm{~kg} / \mathrm{m}^{3}$. It was also revealed that the required FA/CA ratio in order to obtain highest fracture energy was not the same for all fibre contents and fibre aspect ratios. For example, in the $40 \mathrm{~kg} / \mathrm{m}^{3}$ fibre content, the highest fracture energy was obtained from the series having the FA/CA ratio of 1.72 for both fibre aspect ratios. Increasing the FA/CA ratio above this level could not increase the fracture energy anymore, probably due to the excessive increase in specific surface area of aggregates. As the FA/CA ratio and the fibre content increase, more cement paste volume is needed to coat all fibres and the aggregates. Therefore, the available cement paste may not be enough to coat all aggregates as well as the fibres. The insufficient coating of some of the fibres with cement paste may reduce fibre-matrix bond and hence the fracture energy. This is more pronounced for the mixtures reinforced with short fibres of $60 \mathrm{~kg} / \mathrm{m}^{3}$ probably due to the high specific surface area of short fibres (low aspect ratio fibres) compared to long fibres (high aspect ratio). At this fibre content, increasing FA/CA ratio from 1.72 to 2.50 resulted in an increase in fracture energy of mixtures reinforced with high aspect ratio fibres (figure 10a).

For evaluating the fibre effectiveness in the enhancement of fracture energy of plain SCC, fracture energy values of fibered mixtures were divided by their plain concrete fracture energy values. Hence the normalized fracture energy values were obtained for $1 / \mathrm{d}=55$ and $\mathrm{l} / \mathrm{d}=80$ fibered mixtures as shown in figure $10 \mathrm{~b}$ and $\mathrm{c}$, respectively. As observed from figures, the fibre effectiveness in the enhancement of the fracture energy of plain SCC is quite similar for different FA/CA ratios when the fibre dosage is relatively low $\left(20 \mathrm{~kg} / \mathrm{m}^{3}\right)$. However, at higher fibre dosages, FA/CA ratio of the mixture becomes important. At the fibre dosage of $60 \mathrm{~kg} / \mathrm{m}^{3}$, the 


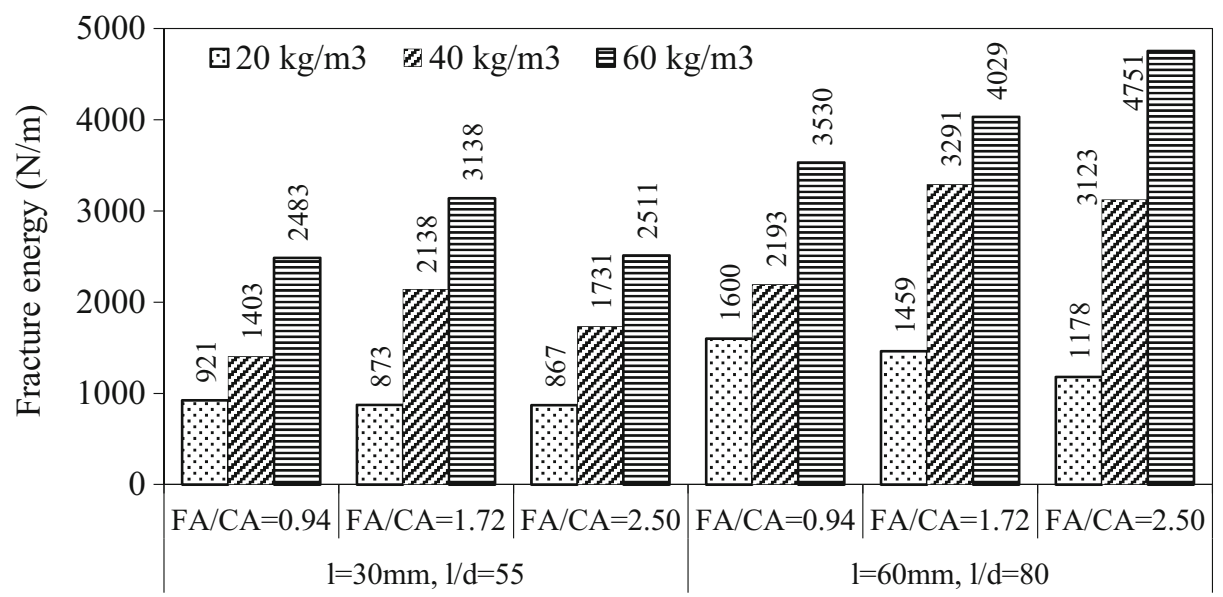

(a)

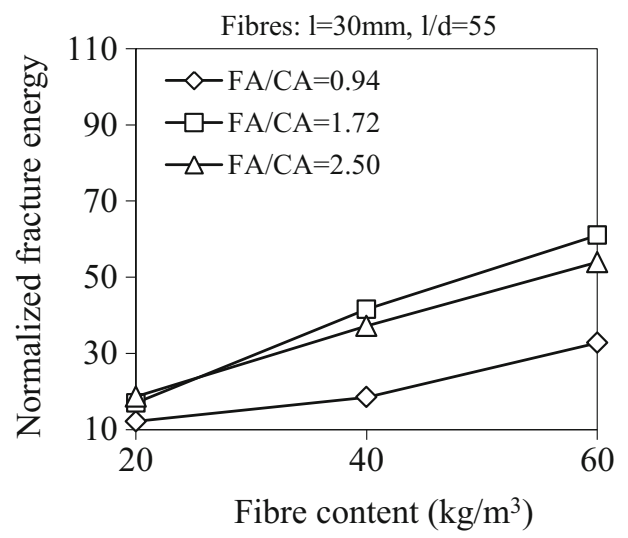

(b)

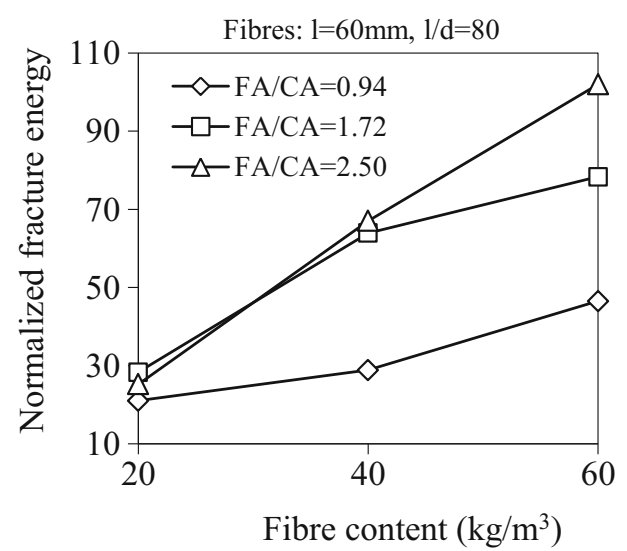

(c)

Figure 10. Effect of fibre content and FA/CA ratio on the fracture energy of SFRSCC mixtures (a), and the effectiveness of $1 / d=55$ (b) and $1 / d=80$ (c) fibres on the enhancement of fracture energy of plain SCC mixtures in different FA/CA ratios.

fracture energy of SFRSCC mixtures having FA/CA ratio of 0.94, is about 33 and 47 times greater than that of its plain SCC for short and long fibres, respectively. This increment of fracture energy is in the order of 54 and 102 times that of plain SCC when the FA/CA ratio increased to 2.50 (figure $10 \mathrm{~b}$ and $\mathrm{c}$ ). This can be attributed to the enhancement of the workability by increasing the FA/CA ratio. This may provide more proper fibre orientation which enables a superior flexural performance as the fibres are bridging the cracks (Bentur \& Mindess 1990; Ferrara \& Meda 2006; Pereira et al 2004). In the scope of this study, a detailed image analysis work on broken pieces remaining from three-point bending test has been carried out aiming to find out the fibre orientation. The details and the methodology of this work can be found in Yardimci (2008). It was seen in this work that a higher orientation number was obtained by increasing the FA/CA ratio particularly in the case of the long fibres at $60 \mathrm{~kg} / \mathrm{m}^{3}$. 
3.2c Relation between flexural parameters and fibre orientation: The relation between the fracture energy of the beam and fibre orientation obtained from cut-sections of the same beam was investigated. The main goal of this part of the study was to find out the influence of the fibre orientation on the presented results. As it is well known, tensile properties of fibre reinforced composites mainly depend on two parameters: (i) number of the fibres present in the crack section and (ii) their orientation with respect to main tensile stress. These two parameters are greatly influenced by the rheological properties (Ferrara \& Meda 2006; Pereira et al 2004) and casting procedure (Torrijos et al 2010). Determining these two parameters is important for better understanding the tensile behaviour of fibre reinforced concrete and also for the analytical modelling of the material. However, it is relatively difficult to evaluate the fibre dispersion in a quantitative manner for a fibre reinforced cementitious matrix. Recently, some effective methods were introduced for evaluating the fibre orientation in concrete such as X-ray technique (Ferrara \& Meda 2006) and an AC-Impedance spectroscopy based method (Ozyurt 2005; Woo et al 2005). The exact number of the fibres can also be defined by manual counting of the fibres present in the cracked plane and the fibre orientation can be evaluated by a method based on the number of fibres in a cracked section. However, it is not quite easy to define the orientation of the fibres with respect to main tensile stress in a cracked section. Furthermore, manual counting of the fibres in a cracked section may also contain some errors such as double counting of the fibres due to possible fibre rupture. For the assessment of fibre orientation on the laboratory-scaled bending samples, a relatively practical and applicable optical method was introduced by Schönlin (1988). This optical method is based on taking the photos of a cross-section of a beam and analysing the fibres by digital image processing techniques. Since the steel fibres reflect and the cementitious matrix absorbs the light, it is relatively easy to distinguish the fibres on a cross-section picture by a proper image analysis technique. Orientation of fibres can be evaluated by means of an orientation number determined by Eq. (3).

$$
\eta_{\theta}=\frac{1}{N_{f}} \cdot \sum_{1}^{N_{f}} \cos \theta,
$$

where $N_{f}$ is the number of steel fibres on the cross-section, $\theta$ is inclination of a fibre relative to the plane of consideration, $\cos \theta=\frac{d_{f}}{L_{f, a c t}}\left(d_{f}\right.$ fibre diameter and $L_{f, a c t}$ appearing fibre length in the cross-section). Orientation number is a number which varies between 0 and 1 . The orientation number of 1 addresses a fibre which is positioned parallel to direction of tensile stress in the beam. In this case the fibre is positioned perpendicular to cut plane and therefore only a circle is visible on the cross section surface as illustrated in figure 11d. An orientation number of 0 shows the fibre is being positioned parallel to cross-section of the beam that has been sawn. Several researchers have used this method to evaluate the orientation of fibres in a cross-section (Grünewald 2004; Markovic 2006; Yardimci 2008).

The portion of beams from the failed specimens in three-point bending test were cut at a distance of 100 and $200 \mathrm{~mm}$ from the crack plane (figure 11a). Therefore, there was no hollow space caused by fibre pull-out on the captured image. At least six cut-surfaces were obtained from three beams used in three-point bending test for each series and the cut-surface photographs were taken in a dark room by a computer-controlled digital camera. In order to distinguish the fibres from the cement matrix, a circular shaped white light source was used. Since the metal fibres reflect the light well, it was very easy to detect the fibres (figure 11b). The cut-plane pictures obtained under a special lighting were analysed by image processing software named 'Image-J' and the 


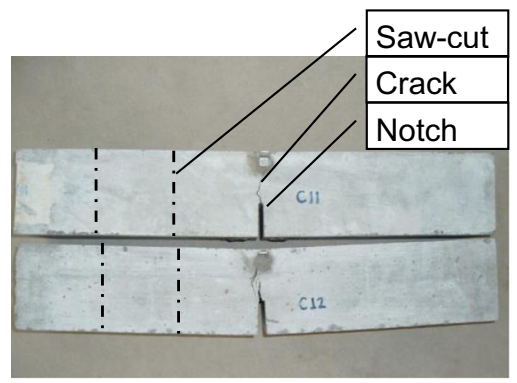

(a)

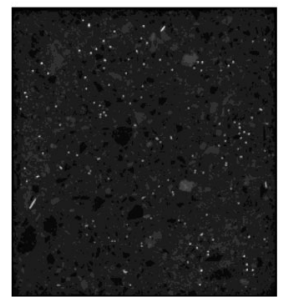

(b)

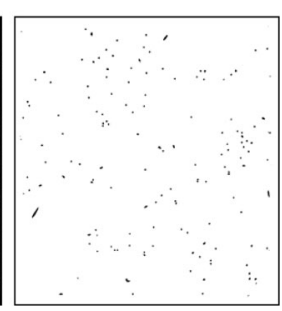

(c)

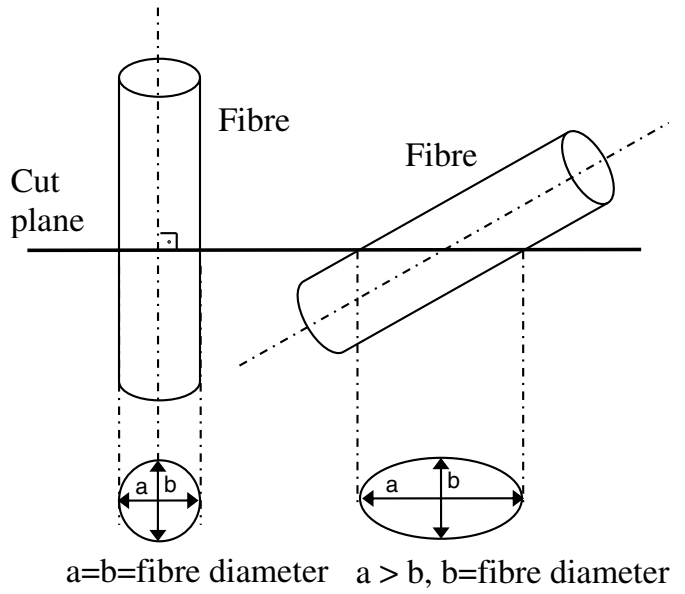

(d) (e)

Figure 11. Cut-planes on the beams used in three-point bending test (a), the original photograph of a sawn cross-section (b), distinguished fibres on the cut-plane by image analysis (c), projections of perpendicular (d) and aligned (e) fibres to the cut-plane.

all fibres on the cut-plane were distinguished from cement matrix by a fine adjustment of grayscale threshold (figure 11c). The number of fibres on the cut-surface and, the minor and major lengths of the reflected fibre areas (figures $11 \mathrm{~d}$ and e) were automatically obtained for each picture. For each cut-surface, the number of fibres and their orientation numbers were determined and their average values defined the average number of fibres and average orientation number for each mixture. These average values have been correlated to the fracture energy for the mixture. Details of the image analysis procedure can be found in Yardimci (2008). Some other researchers had correlated the toughness parameters with the number of fibres intersecting the fracture surface in bending (Vandewalle \& Dupont 2003) and uni-axial tensile tests on cylindrical specimens (Gettu \& Barragan 2003). On the other hand, Gettu \& Barragan (2003) had reported no correlation in case of the first peak stress or tensile strength. Figure 12 shows the relationship between the number of fibres per $\mathrm{cm}^{2}$ and flexural strength and fracture energy. Although these curves have been plotted without regarding FA/CA ratio differences in the mixtures, a relatively strong correlation between the number of the fibres per $\mathrm{cm}^{2}$ and flexural parameters was obtained for both types of fibres. This shows the importance of the presence of fibres in the cross-section in terms of flexural performance of fibre reinforced composites as similarly shown by the other researchers (Zerbino et al 2012).

Besides the number of fibres in the cross-section of a beam, the orientation of the fibres with respect to main tensile stress is also important. Grünewald (2004) showed that the longer the fibre is, the higher is the orientation number, therefore the performance of beams with longer fibres is more favourably affected by the orientation of the fibres, and suggested a single-parameter model for SFRSCC mixtures as $\eta_{\theta}=0.698+1.77 .10^{-3} \cdot L_{f}$ to predict the orientation number $\left(L_{f}\right.$ is the length of the fibre). The obtained orientation numbers with respect to fibre length are shown in figure 13 with the orientation number calculated based on the Grünewald's model (black 


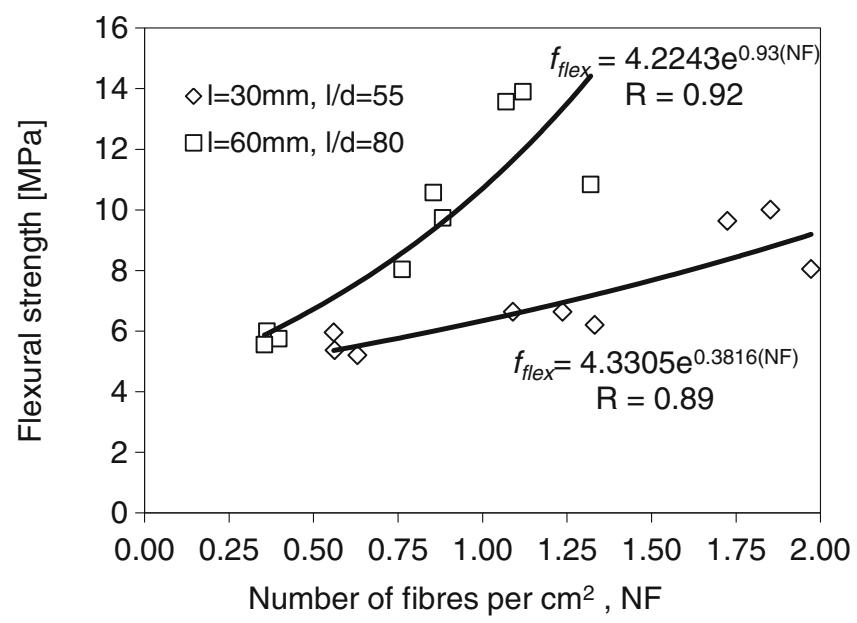

(a)

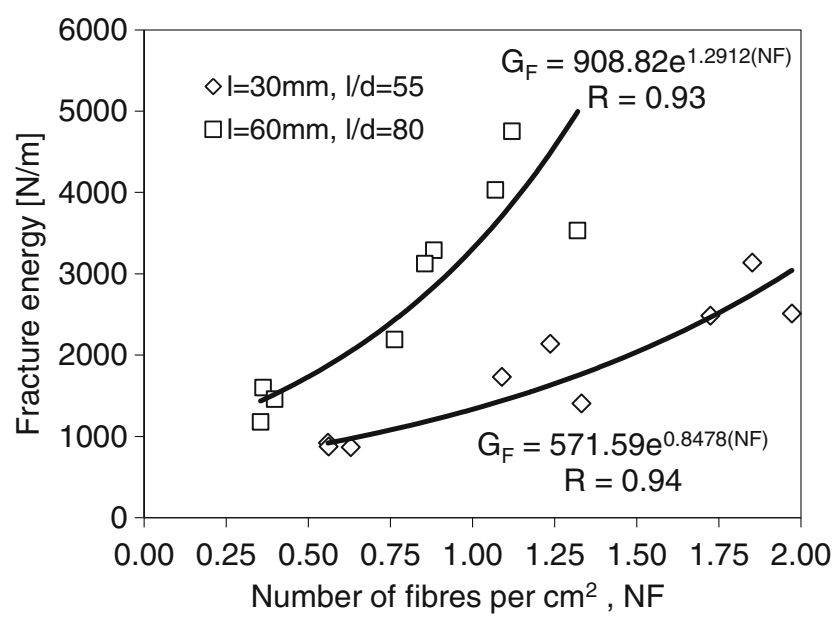

(b)

Figure 12. The number of fibres per unit area vs. flexural strength (a) and fracture energy (b) relations for $1 / \mathrm{d}=55$ and $1 / \mathrm{d}=80$ fibres.

points in figure 13). As can be seen from figure, as a general trend, relatively higher orientation numbers were obtained for longer fibres as parallel to Grünewald's model (Grünewald 2004). On the other hand, the orientation numbers obtained for $30 \mathrm{~mm}$ and $60 \mathrm{~mm}$ fibre cases in this study were in the range of $0.63-0.78$ and $0.71-0.83$, respectively and seems not to be expressed by a single model for SFRSCC mixtures having different FA/CA ratios.

Variation of the orientation number with respect to FA/CA ratio and the fibre content is presented for $1 / \mathrm{d}=55$ and $\mathrm{l} / \mathrm{d}=80$ fibre cases in figures $14 \mathrm{a}$ and $\mathrm{b}$, respectively. As can be seen from figures, increasing the fibre content has resulted in an increase in orientation number for all FA/CA ratios with an exceptional case for longer fibres used in the mixture having FA/CA of 0.94 in relatively high dosage $\left(60 \mathrm{~kg} / \mathrm{m}^{3}\right)$. Relatively poor flow properties of this mixture in high fibre dosages (figures 1 and 5) may cause a decreased orientation number. For the other series, 


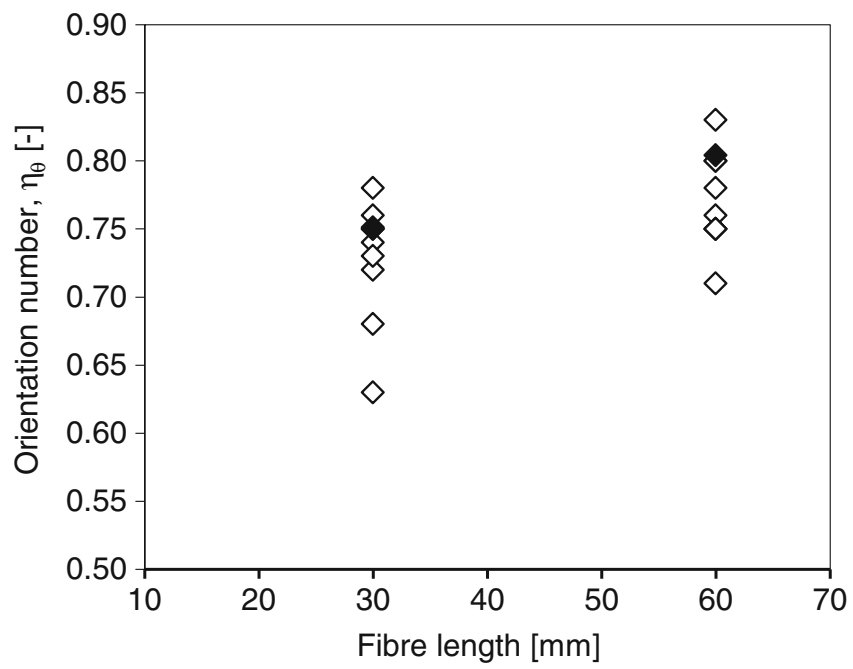

Figure 13. Fibre length - orientation number relation (black points represent the orientation number calculated based on Grünewald's (Grünewald 2004) model).

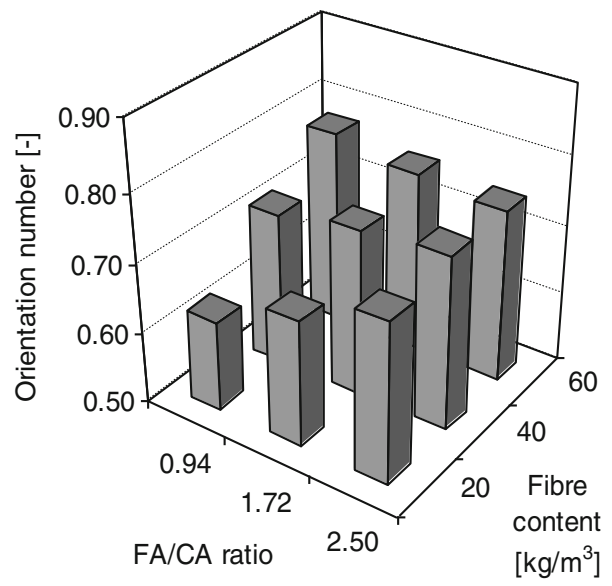

(a)

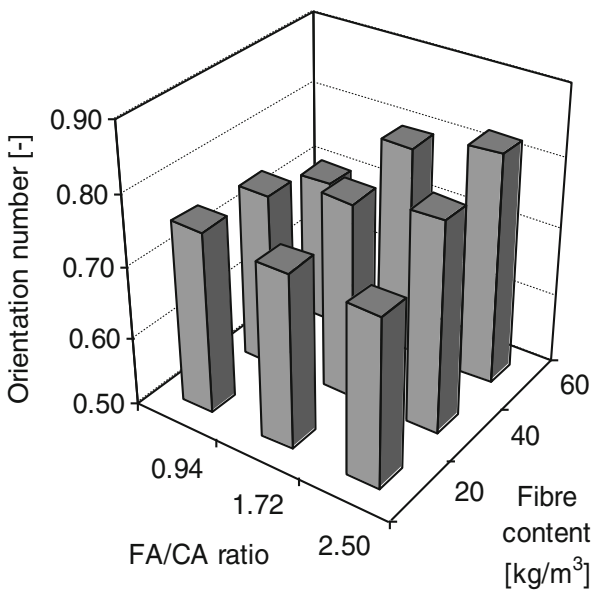

(b)

Figure 14. The effect of FA/CA ratio and fibre content on orientation number for $1=30 \mathrm{~mm}, 1 / \mathrm{d}=55$ (a) and $1=60 \mathrm{~mm}, 1 / \mathrm{d}=80$ (b) fibred series.

more fibres were preferably aligned into the direction of the flow when the fibre content was relatively high. On the other hand, a significant wall-effect in small beams may lead to obtain the higher orientation number in the longer fibre case as mentioned by other researchers (Grünewald 2004; Vandewalle \& Dupont 2003). At a relatively low fibre content $\left(20 \mathrm{~kg} / \mathrm{m}^{3}\right)$, the lowest orientation number was obtained in the series having FA/CA ratio of 0.94 for $30 \mathrm{~mm}$ fibre case. Increasing the FA/CA ratio from 0.94 to 2.50 has resulted in a considerably higher orientation number $(0.63$ vs. 0.73$)$ at this dosage. However, this did not result in higher flexural strength (figure 9a) or fracture energy (figure 10a). Similarly, in the case of $60 \mathrm{~mm}$ fibres at this dosage $\left(20 \mathrm{~kg} / \mathrm{m}^{3}\right)$, the orientation numbers for all cases of grading were very close to each other but 


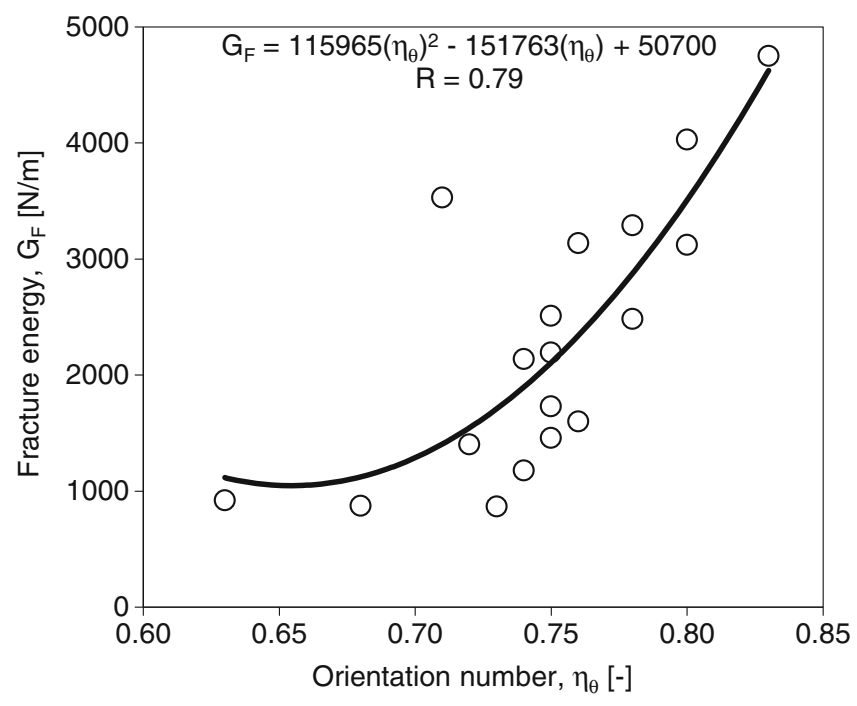

Figure 15. Orientation number, $\eta_{\theta}-$ fracture energy, $\mathrm{G}_{\mathrm{F}}$ relation for all series.

flexural strength and fracture energy of the grading series followed the trend of their plain concrete values (table 4, figures 9a and 10a). These findings clearly indicate the matrix-dominated behaviour at a relatively low fibre dosage such as $20 \mathrm{~kg} / \mathrm{m}^{3}$ i.e., increasing FA/CA ratio decreases the mechanical properties regardless of the fibre alignment. In high fibre dosages $\left(60 \mathrm{~kg} / \mathrm{m}^{3}\right)$ increasing the FA/CA ratio of the mixture increased the orientation number. It can be concluded that the combined influence of the aggregate grading and fibre length and content, define the orientation of fibres in SFRSCC. The correlation between orientation number and fracture energy is shown in figure 15. It should be emphasized that the figure was plotted without regarding the FA/CA ratio, fibre content and differences in type of series in the scope of this study. As a general trend, it is evident that fracture energy increases as the orientation number increases and the fracture energy can be defined by a second order one-parameter model based on the orientation number.

\section{Conclusions}

In the presented study, the following conclusions can be drawn. Steel fibre inclusion to plain SCC mixtures negatively affects the rheological parameters, particularly the passing ability of the mixture. This trend is more pronounced when high aspect ratio fibres used in high content. Increasing FA/CA ratio from 0.94 to 2.50 enhances the flowability and the passing ability of SFRSCC mixtures with a powder content of $580 \mathrm{~kg} / \mathrm{m}^{3}$. It was observed that the poor flowability and the passing ability of SFRSCC mixtures containing high aspect ratio fibres in $60 \mathrm{~kg} / \mathrm{m}^{3}$ dosage can be enhanced by increasing the FA/CA ratio from 0.94 to 2.50 .

As a contrary to the existing literature for conventionally vibrated concrete, fibre inclusion to plain SCC may cause a significant compressive strength loss when the coarse grading was used (low FA/CA ratio). This trend was less valid in the series having relatively high FA/CA ratios. 
Compressive strength alteration due to fibre inclusion is around $10 \%$ or less in the SFRSCC series when the FA/CA ratio is higher than 1.72 .

FA/CA ratio of plain SCC mixture has an important effect on fracture energy i.e., the fracture energy of plain SCC significantly decreases as the FA/CA ratio increases. This trend is not the same for SFRSCC with fibre contents of 40 and $60 \mathrm{~kg} / \mathrm{m}^{3}$. It was found that the FA/CA ratio higher than 1.72 should be used to obtain high level of fracture energy when the fibre contents are 40 and $60 \mathrm{~kg} / \mathrm{m}^{3}$. This is also found to be more pronounced for high aspect ratio fibres.

Increasing the FA/CA ratio of a SCC mixture, whose workability is not significantly influenced by fibre inclusion, may decrease the mechanical performance. Therefore, the proper FA/CA ratio for the best rheological and mechanical performance depends on the fibre content, aspect ratio and their influence on the workability of the mixture. As a general trend, it can be concluded that higher FA/CA ratio should be used when the fibre content and aspect ratio are high.

A strong correlation exists between the number of fibres per unit area and flexural parameters (flexural strength and fracture energy). Image analysis studies showed that a greater number of low aspect ratio fibres are needed in the cracked section to have the similar level of flexural parameters obtained with high aspect ratio fibres.

Fracture energy of SFRSCC increases as the orientation number increases. The finer grading (higher FA/CA ratio) provides better orientation in SFRSCC mixtures containing high aspect ratio fibres in high content.

\section{Acknowledgements}

The authors thank Mr İrfan Kadiroglu of Izmir Batı Beton Ready-Mixed Concrete Company for their extensive help during concrete production. Authors also thank Mr. Mehmet Yerlikaya from Bekaert-Beksa -Turkey for providing fibres used in this study. Dr. Okan Onal from Dokuz Eylul University is also thanked for his valuable suggestions on the image analysis set-up.

\section{References}

ACI 544.1R-96 1997 State-of-the-Art Report on Fiber Reinforced Concrete, American Concrete Institute. ACI Committee 544

Appa Rao G and Raghu Prasad B K 2002 Fracture energy and softening behavior of high-strength concrete. Cement and Concrete Research 32: 247-252

Bayramov F, Tasdemir C and Tasdemir M A 2004 Optimisation of steel fibre reinforced concretes by means of statistical response surface method. Cement \& Concrete Composites 26(6): 665-675

Benabed B, Kadri E H, Azzouz L and Kenai S 2012 Properties of self-compacting mortar made with various types of sand. Cement and Concrete Composites 34: 1167-1173

Bentur A and Mindess S 1990 Fiber reinforced cementitious composites. E\&FN SPON, UK, 1st edition

Boulekbache B, Hamrat M, Chemrouk M and Amziane S 2009 Flowability of fibre-reinforced concrete and its effect on the mechanical properties of the material. Construction and Building Materials 24(9): $1664-1671$

Chen B and Liu J 2004 Effect of aggregate on the fracture behavior of high strength concrete. Construction and Building Materials 18(8): 585-590

EFNARC 2002 Specification and guidelines for self-compacting concrete. English ed, Norfolk, UK: European Federation for Specialist Construction Chemicals and Concrete Systems

EFNARC 2005 The European Guidelines for Self-Compacting Concrete, Specification, production and use. SCC European Project Group 
El-Dieb A S and Reda Taha M M 2012 Flow characteristics and acceptance criteria of fiber-reinforced self-compacted concrete (FR-SCC). Construction and Building Materials 27: 585-596

Eren Ö and Çelik T 1997 Effect of silica fume and steel fibers on some properties of high-strength concrete. Construction and Building Materials 11(7-8): 373-382

Ferrara L and Meda A 2006 Relationships between fibre distribution, workability and the mechanical properties of SFRC applied to precast roof elements. Materials and Struct 39: 411-420

Ferrara L, Bamonte P, Caverzan A, Musa A and Sanal I 2012 A comprehensive methodology to test the performance of Steel Fibre Reinforced Self-Compacting Concrete (SFR-SCC). Construction and Building Materials 37: 406-424

Ferrara L, Park Y D and Shah S P 2007 A method for mix-design of fiber-reinforced self-compacting concrete. Cement and Concrete Res. 37(6): 957-971

Gettu R and Barragan B E 2003 Direct Tension Test and Interpretation. RILEM publication PRO 31. Test and Design Methods for Steel Fibre reinforced Concrete - Background and Experiences, pp. 15-30

Gomes P C C 2002 Optimization and characterization of high-strength self-compacting concrete, PhD Thesis, Universitat Politechnica De Catalunya, Barcelona, Spain

Groth P 2000 Fibre reinforced concrete - Fracture mechanics methods applied on self-compacting concrete and energetically modified binders PhD Thesis. Lulea University of Technology, Sweden

Grünewald S and Walraven J C 2001 Parameter - study on the influence of steel fibers and coarse aggregate content on the fresh properties of self - compacting concrete. Cement and Concrete Research 31: $1793-1798$

Grünewald S 2004 Performance-based design of self-compacting fibre reinforced concrete. PhD Thesis, Delft University of Technology, Delft, Netherlands

Hillerborg A 1983 Concrete fracture energy tests performed by 9 laboratories according to a draft RILEM recommendation. Report to RILEM TC50 -FMC. Lund Institute of Technology, Sweden

Johnston C D 1996 Proportioning, mixing and placement of fibre-reinforced cements and concretes. Production Methods and Workability of Concrete. Edited by Bartos. Marrs and Cleland. E\&FN Spon. London. pp. 155-179

Khayat K H 1999 Workability, testing and performance of self-compacting concrete. ACI Materials J. 96(3): 346-353

Khayat K H and Roussel Y 2000 Testing and performance of fiber reinforced self consolidating concrete. Materials and Struct. 33: 391-397

Kim D J, Naaman A E and El-Tavil S 2008 Comparative flexural behavior of four fiber reinforced cementitious composites. Cement and Concrete Composites 30: 917-928

Löfgren I 2005 Fibre-reinforced Concrete for Industrial Construction - a fracture mechanics approach to material testing and structural analysis. PhD Thesis, Department of Civil and Environmental Engineering Structural Engineering Chalmers University of Technology, Sweden

Markovic I 2006 High-performance hybrid fibre concrete: Development and utilization. PhD Thesis, Delft University of Technology, The Netherlands

Naaman A E and Reinhardt H W 2006 Proposed classification of HPFRC composites based on their tensile response. Materials and Struct. 39(5): 547-555

Neville A M 1995 Properties of concrete. Longman Group, $4^{\text {th }}$ Edition, London

Ozyurt N 2005 Connecting fiber dispersion, rheology and mechanical performance for fiber reinforced cement based materials. PhD Thesis, Istanbul Technical University, Turkey

Pajak M and Ponikiewsky T 2013 Flexural behavior of self-compacting concrete reinforced with different types of steel fibers. Construction and Building Materials 47: 397-408

Pereira de Oliveira, L A, Castro Gomes J P, Bernardo L F A and Ramos M M M 2013 Evaluation of dry mortar ratio as mix design parameter for steel fibre reinforced self compacting concrete. Construction and Building Materials 40: 642-649

Pereira E N B, Barros J A O, Ribeiro A F and Camoes A 2004 Post cracking behavior of self compacting steel fiber reinforced concrete. Proceedings BEFIB04, Paris, RILEM Pubs. pp. 1371-1380

RILEM T C, 50-FMC 1985 Determination of Fracture Energy of Mortar and Concrete by Means of ThreePoint Bend Tests on Notched Beams. Materials and Structures 18(106): 285-290 
Schönlin K 1988 Ermittlung der Orientierung, Menge und Verteilung der Fasern in faserbewehrtem Beton. Beton- und Stahlbetonbau 83(6): 168-171

Shah S P, et al 1978 Complete Stress-Strain Curves for Steel Fibre Reinforced Concrete in Uniaxial Tension and Compression. Proceedings, RILEM Symposium on Testing and Test Methods of Fibre Cement Composites, Construction Press Ltd. pp. 399-408

Swamy R N 1975 Fibre reinforcement of cement and concrete. Materials and Structures 8(45): 235-254

Swamy R N and Mangat P S 1974 Influence of fibre-aggregate interaction on some properties of steel fibre reinforced concrete. Materials and Structures 7(41): 307-314

Thomas J and Ramaswamy A 2007 Mechanical properties of steel fiber-reinforced concrete. J. Mater. Civ. Eng., 19(5): 385-392

Torrijos M C, Barragan B E and Zerbino R L 2010 Placing conditions, mesostructural characteristics and post-cracking response of fibre reinforced self-compacting concretes. Construction and Building Materials 24: 1078-1085

Vandewalle L and Dupont D 2003 Bending Test and Interpretation, RILEM publication PRO 31 Test and Design Methods for Steel Fibre reinforced Concrete - Background and Experiences, pp. 1-14

Wittmann F H 2002 Crack formation and fracture energy of normal and high strength concrete. Sadhana 27(4): 413-423

Woo L Y, Wansom S, Ozyurt N, Mu B, Shah S P and Mason T O 2005 Characterizing fiber dispersion in cement composites using AC-Impedance Spectroscopy. Cement and Concrete Composites 27: 627-636

Yardimci M Y 2008 Investigation of rheological, mechanical, fracture parameters and optimum design of steel fiber reinforced self-compacting concretes, PhD Thesis, Dokuz Eylul University (In Turkish with an English abstract)

Zerbino R, Tobes J M, Bossio M E and Giaccio G 2012 On the orientation of fibres in structural members, fabricated with self compacting fibre reinforced concrete. Cement and Concrete Composites 34: $191-200$ 